\title{
Discovery of the first potent and selective inhibitors of the human dCTP pyrophosphatase 1 (dCTPase)
}

Sabin Llona-Minguez,,$^{\dagger \ddagger}$ Andreas Höglund, ${ }^{\dagger \ddagger}$ Sylvain A. Jacques, ${ }^{\dagger}$ Lars Johansson, ${ }^{\dagger}{ }^{\#}$ José Manuel Calderón-Montaño, ${ }^{\dagger}$ Magnus Claesson, ${ }^{\infty}$ Olga Loseva, ${ }^{\dagger}$ Nicholas C.K. Valerie ${ }^{\dagger}{ }^{\text {Thomas Lundbäck, }},{ }^{\dagger}$ Javier Piedrafita, ${ }^{\overline{ }}$ Giovanni Maga, ${ }^{\S}$ Emmanuele Crespan, ${ }^{\S}$ Laurent Meijer, "Estefanía Burgos Morón, ${ }^{\dagger}$ Pawel Baranczewski, ${ }^{\dagger \nabla}$ Ann-Louise Hagbjörk, ${ }^{\nabla}$ Richard Svensson, ${ }^{\nabla}$ Elisee Wiita, ${ }^{\dagger}$ Ingrid Almlöf, ${ }^{\dagger}$ Torkild Visnes, ${ }^{\dagger}$ Fredrik Jeppsson, ${ }^{\dagger}$ Kristmundur Sigmundsson, ${ }^{\dagger \#}$ Annika Jenmalm Jensen, ${ }^{\dagger \#}$ Per Artursson, ${ }^{\nabla}$ Ann-Sofie Jemth, ${ }^{\dagger}$ Pål Stenmark, ${ }^{\infty}$ Ulrika Warpman Berglund,${ }^{\dagger}$ Martin Scobie, ${ }^{\dagger}$ and Thomas Helleday. ${ }^{\dagger *}$

${ }^{\dagger}$ Division of Translational Medicine and Chemical Biology, Science for Life Laboratory, Department of Medical Biochemistry and Biophysics, Karolinska Institutet, Stockholm, Sweden

${ }^{\#}$ Chemical Biology Consortium Sweden, Science for Life Laboratory, Division of Translational Medicine and Chemical Biology, Department of Medical Biochemistry and Biophysics, Karolinska Institutet, Stockholm, Sweden.

${ }^{\nabla}$ Uppsala University Drug Optimization and Pharmaceutical Profiling Platform Department of Pharmacy, Science for Life Laboratory, Uppsala University, Uppsala, Sweden

${ }^{\infty}$ Department of Biochemistry and Biophysics, Stockholm University, Svante Arrhenius väg 16C, SE10691 Stockholm, Sweden.

${ }^{\S}$ Istituto di Genetica Molecolare, IGM-CNR, Via Abbiategrasso 207, 27100 Pavia, Italy

"ManRos Therapeutics, Perharidy Research Center, 29680 Roscoff, Bretagne, France

${ }^{\bar{T}}$ Torrey Pines Institute for Molecular Studies, 3550 General Atomics Ct., San Diego, CA 92121, United States

\section{Supporting Information}




\section{TABLE OF CONTENTS}

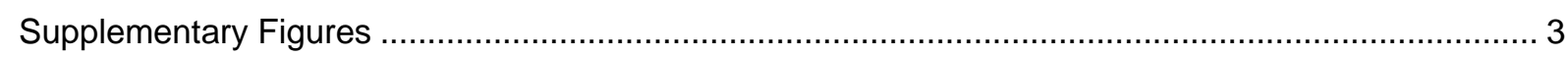

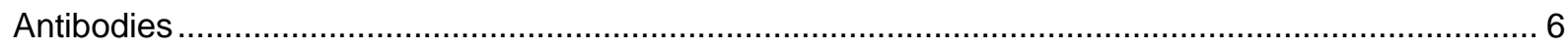

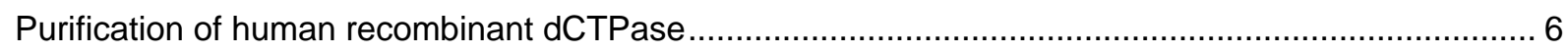

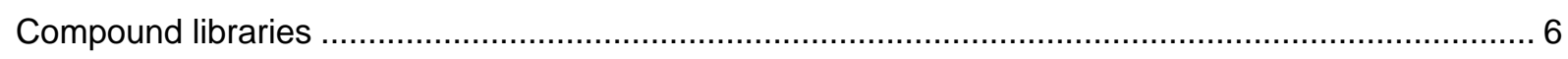

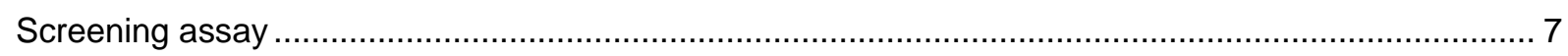

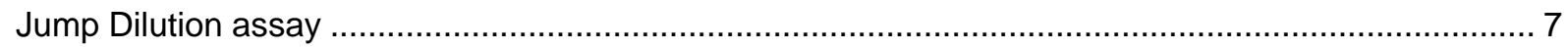

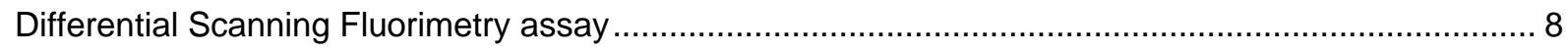

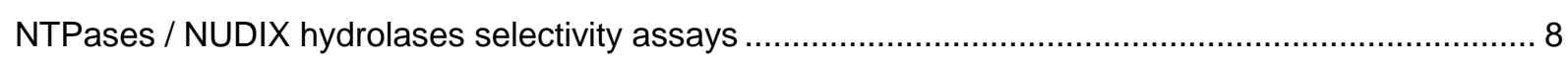

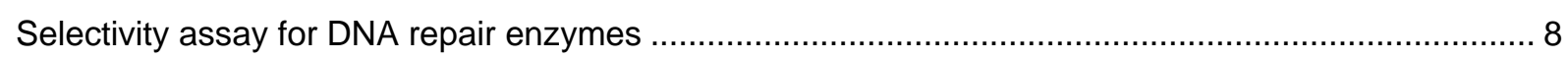

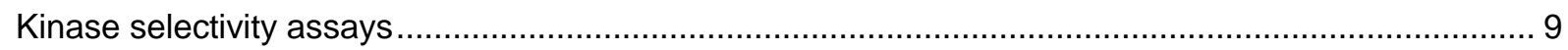

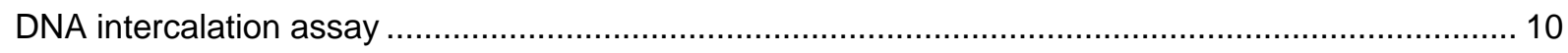

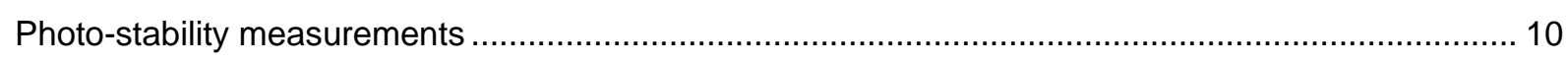

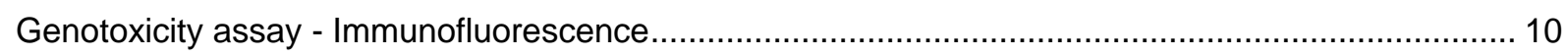

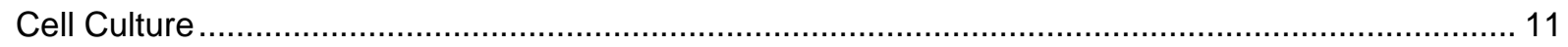

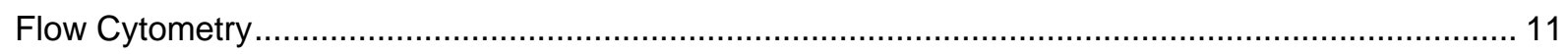

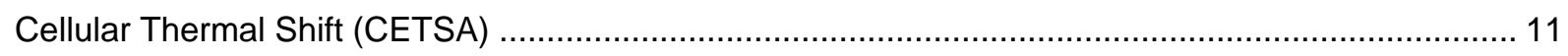

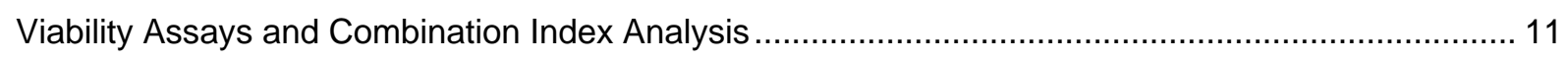

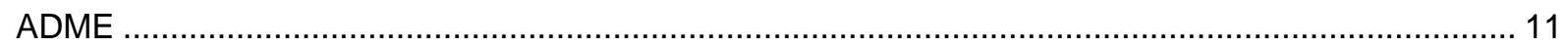

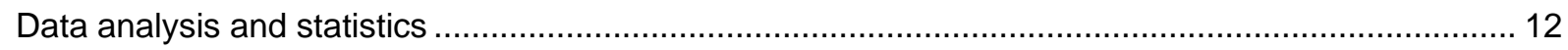

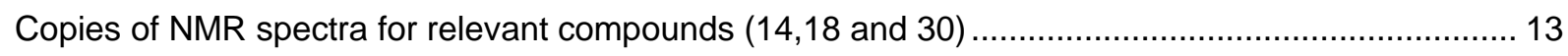

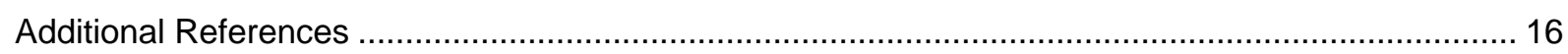




\section{Supplementary Figures}

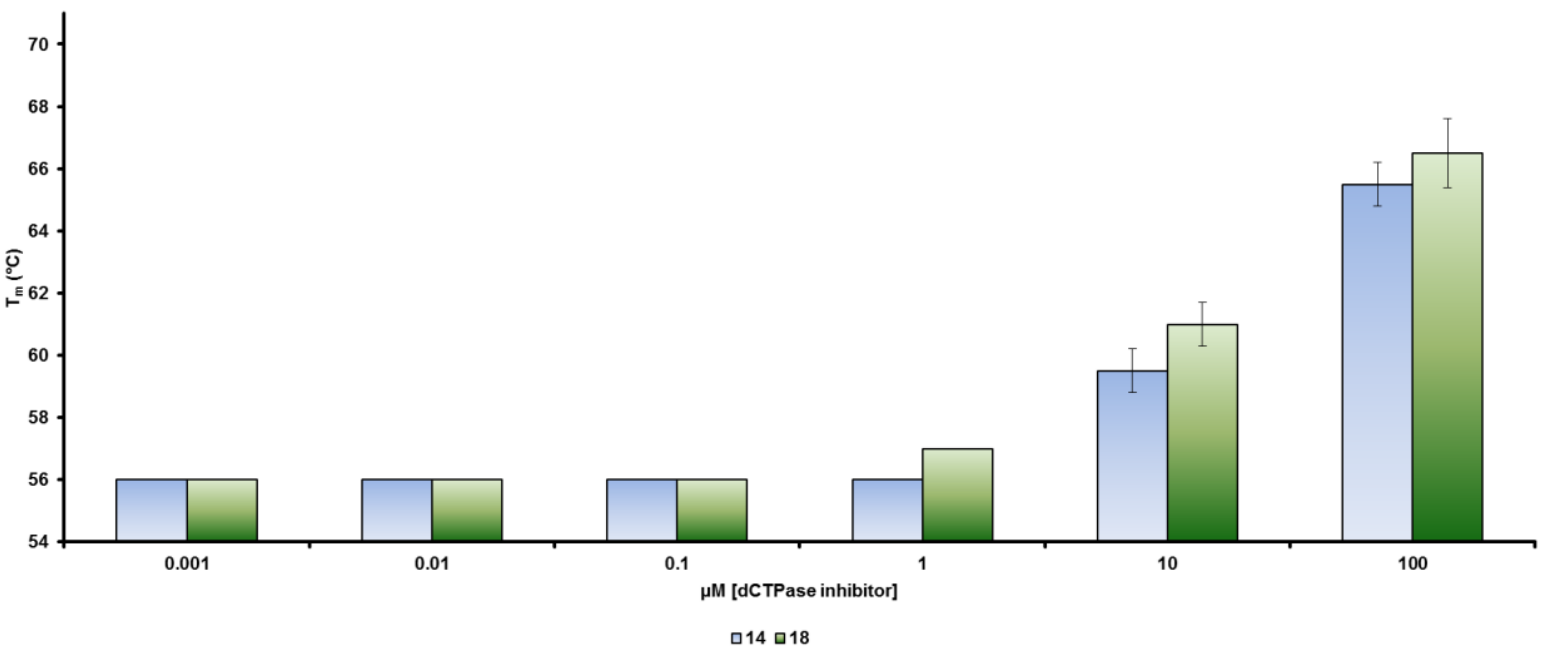

Figure 1. dCTPase inhibitors $\mathbf{1 4}$ and $\mathbf{1 8}$ stabilize dCTPase. Purified dCTPase was exposed to increasing concentrations of dCTPase inhibitors and the $T_{m}$ was measured using the Differential Scanning Fluorimetry assay.
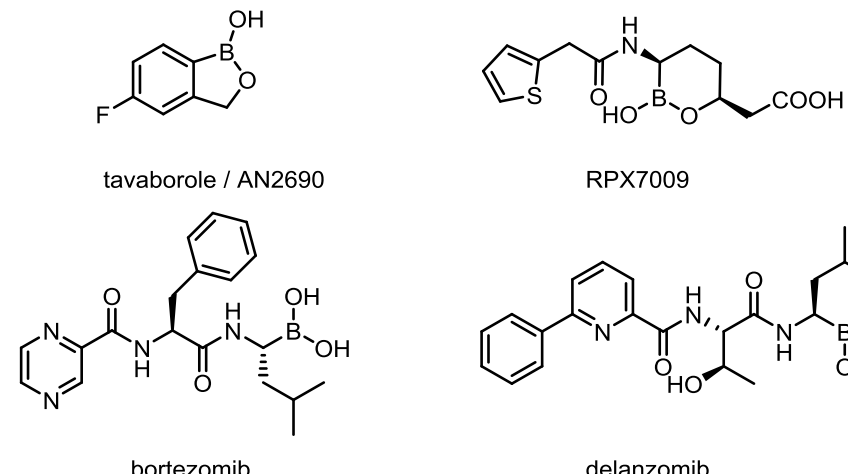

RPX7009

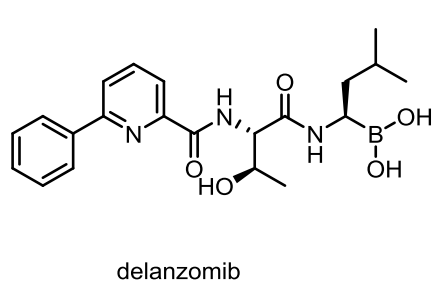

Figure 2. Structures of boron-containing drugs. 
A

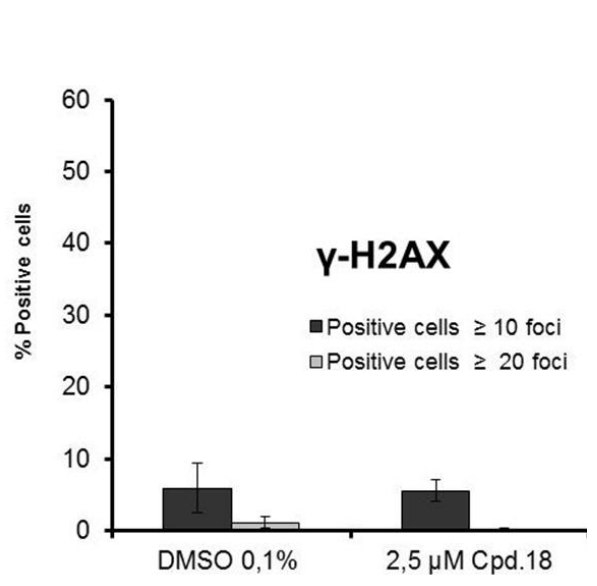

B

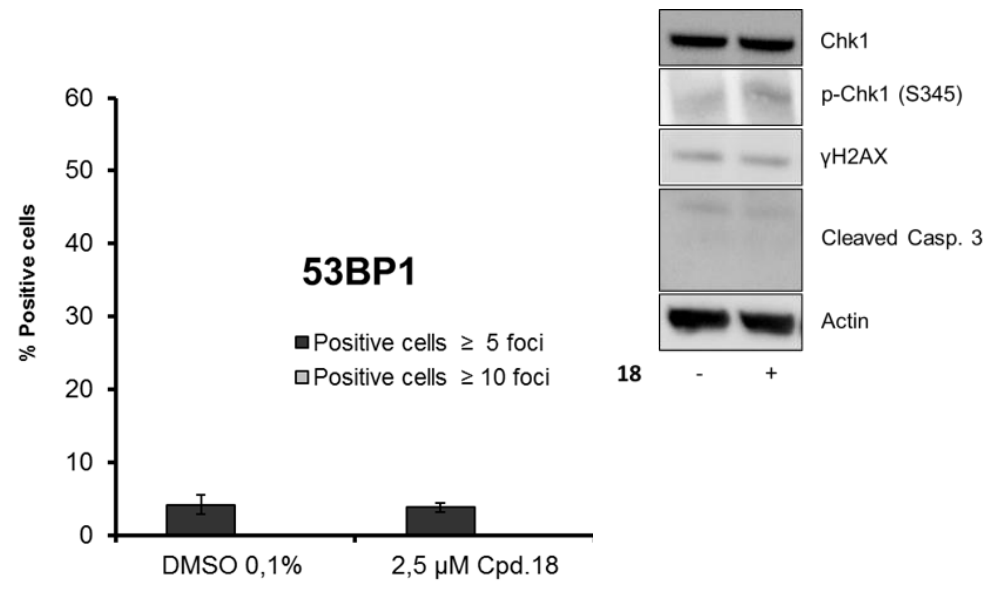

Figure 3. dCTPase inhibitor 18 does not induce DNA damage. A) AML HL60 cells were treated for 24h with low dose 18 and then quantified for the formation of $\mathrm{YH} 2 \mathrm{AX}$ and 53BP1 foci using fluorescence microscopy. B) $\mathbf{1 8}$ does not induce DNA damage ( $\mathrm{YH} 2 \mathrm{AX}$ or $\mathrm{p}$-Chk1) or apoptosis (Cleaved caspase 3 ) by Western blot detection.

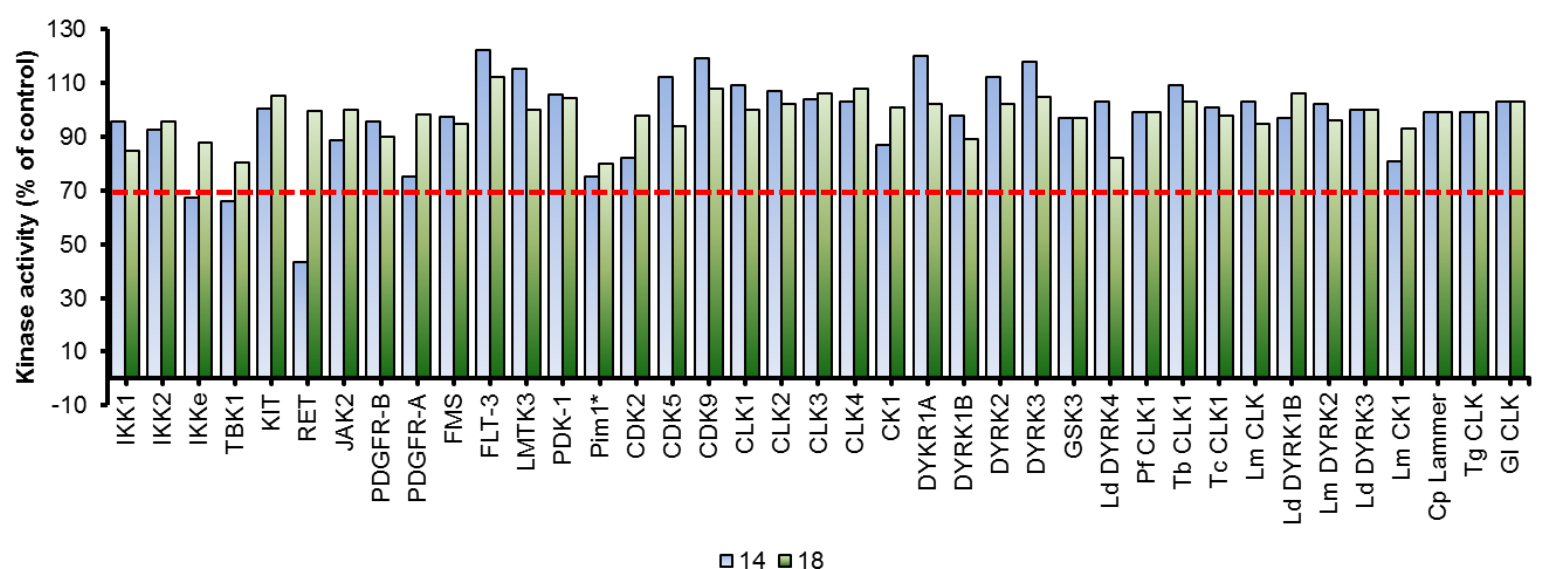

Figure 4. Selectivity profile for compounds 14 and 18: Kinase enzymes. Tested at $10 \mu \mathrm{M}$; red dotted line indicates $30 \%$ inhibition level. ${ }^{*}$ Tested at $100 \mu \mathrm{M}$. 


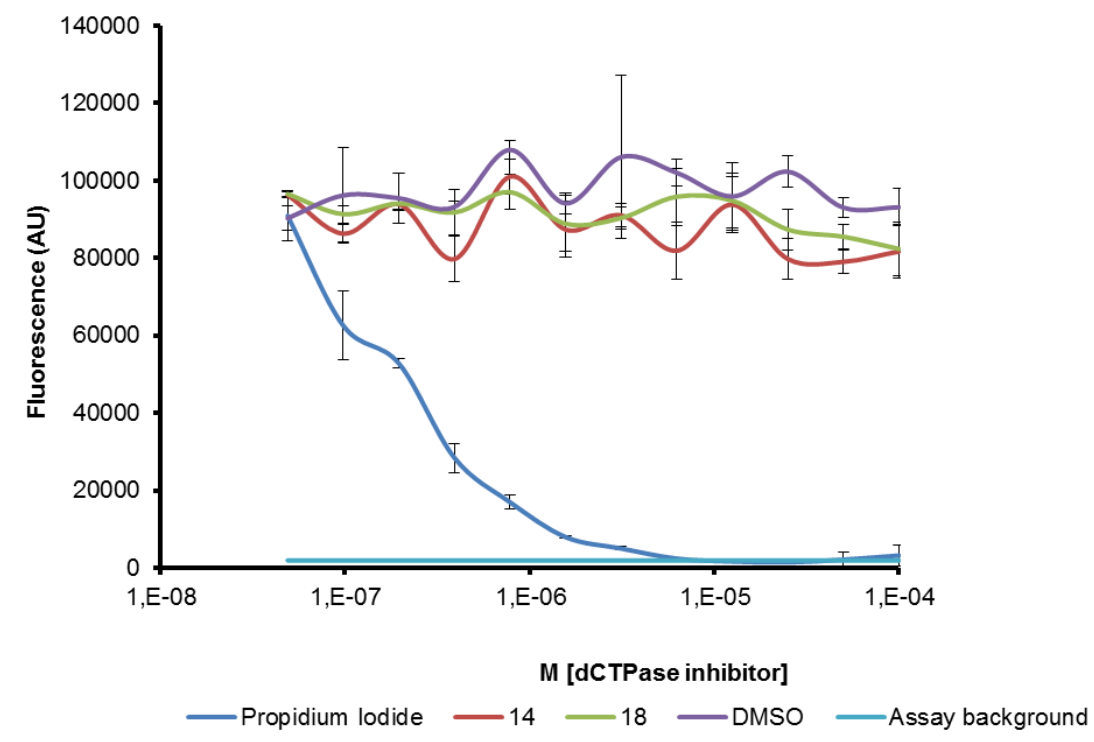

Figure 5. DNA intercalation measured by thiazole orange displacement. The DNA intercalator propidium iodide displaces thiazole orange and leads to a decrease in fluorescence to background levels.<smiles>Cn1c(C2CC(O)C(O)O2)nnc(N)c1=O</smiles>

decitabine<smiles>Nc1nnc(C(O)C(O)CO)n(C2OCC(O)O2)c1=O</smiles>

5-azacytidine<smiles>Nc1ccn(C2OC3(CO)CC(O)C2O3)c(=O)n1</smiles>

gemcitabine

Figure 6. Structures of cytidine analogues.

$\begin{array}{lcc} & \mathbf{1 4} & \mathbf{1 8} \\ \text { MTH1 } & >100 & 6.8 \\ \text { NUDT2 } & >100 & >100 \\ \text { NUDT5 } & >100 & >100 \\ \text { NUDT9 } & >100 & >100 \\ \text { NUDT12 } & >100 & >100 \\ \text { NUDT14 } & >100 & >100 \\ \text { NUDT15 } & >100 & >100 \\ \text { ITPase } & >100 & >100 \\ \text { dUTPase } & >100 & >100 \\ \text { dCTPase } & 0.041 & 0.046\end{array}$

Table 1. Selectivity profile for compounds $\mathbf{1 4}$ and $\mathbf{1 8}$ towards NTPases and NUDIX enzymes.

Expressed as $\mathrm{IC}_{50}$ values $(\mu \mathrm{M})$. 


$\begin{array}{lcc} & \mathbf{1 4} & \mathbf{1 8} \\ \text { APE1 } & >100 & >100 \\ \text { E.Coli Fpg } & >100 & >100 \\ \text { NEIL1 } & >100 & >100 \\ \text { MPG } & >100 & >100 \\ \text { OGG1 } & >100 & >100 \\ \text { SMUG1 } & >100^{\mathrm{a}} & >100 \\ \text { UNG2 } & >100 & >100\end{array}$

Table 2. Selectivity profile for compounds $\mathbf{1 4}$ and $\mathbf{1 8}$ towards selected base excision repair enzymes and DNA intercalation, expressed as $\mathrm{IC}_{50}$ values $(\mu \mathrm{M})$. ${ }^{\mathrm{a}} \mathrm{Full}$ inhibition is not observed, $50 \%$ inhibition plateau at $100 \mu \mathrm{M}$.

\section{Antibodies}

Purified hsdCTPase was applied for polyclonal antibody production in EZBiolabs, USA. dCTPase Ab was purified from rabbit serum on a home-made affinity column with immobilized dCTPase using AminoLinkTM Immobilization Kit (44890, Thermo Scientific). Primary antibodies used: anti-Actin (AC15, ab6276, Abcam), Anti-phospho-histone $\operatorname{H2AX}$ (S139, 05-636, Millipore), anti-53Bp1 (A300-272A, Bethyl Laboratories), cleaved caspase 3 (AB3623, Millipore), anti-Chk1 (\#2360, Cell Signaling), antiphospho Chk1 (S345) (\#2341, Cell signalling), goat anti-mouse IgG Alexa Fluor® 488 (A11029, Life technologies), donkey anti-rabbit IgG IgG Alexa Fluor ${ }^{\circledR} 555$ (A31572, Life technologies), donkey antirabbit IRDye 680RD (925-68073, LiCor) and donkey anti-mouse 800CW (925-32212, LiCor).

\section{Purification of human recombinant dCTPase}

Human hdCTPase was cloned into a modified pET28 vector (Novagen) with double N-terminal His-tag and TEV protease cleavage site separated from the protein sequence. This construct was transformed into E. coli strain BL21(DE3)pLysS, the bacteria was grown in LB medium at $37^{\circ} \mathrm{C}$ and dCTPase expression was induced by addition of IPTG to a final concentration of $0.5 \mathrm{mM}$ for $2 \mathrm{~h}$. His-tagged dCTPase was purified by immobilized metal ion affinity chromatography (IMAC) using a Ni-Sepharose HisTrap column (GE Healthcare). The His-tag was removed by TEV protease digestion at $4{ }^{\circ} \mathrm{C}$ for 24 $\mathrm{h}$ followed by passing the digested protein through a HisTrap FF column. Finally, dCTPase was purified using a monoQ column HP, dialyzed against $20 \mathrm{mM}$ HEPES pH 7.5, $300 \mathrm{mM} \mathrm{NaCl}, 1 \mathrm{mM}$ TCEP, $10 \%$ glycerol and kept at $-80^{\circ} \mathrm{C}$.

\section{Compound libraries}

Screening for inhibitors of human recombinant dCTPase was done at Chemical Biology Consortium Sweden (CBCS) using $10 \mu \mathrm{M}$ compound concentration in 96-well microtiter plates. The screen campaign was based on a diversity set of small molecule compounds (kindly donated by Biovitrum $A B$, Sweden). All assay plates contained negative (wells A12-D12) and positive controls (wells E12-H12), 
where negative controls represent uninhibited enzyme, corresponding to wells with the equivalent amount of DMSO as the compound containing wells, and positive controls represent the completely inhibited enzyme, corresponding to wells containing 20 mM EDTA (thus chelating all magnesium ions). The compound stock solutions were stored frozen at $-20{ }^{\circ} \mathrm{C}$ in REMP 96 Storage Tube Racks, where each solution is stored in an individual capped tube containing up to $200 \mu \mathrm{l}$. The racks were stored in a REMP Small-Size Store ${ }^{\mathrm{TM}}$. To enable the flexibility to screen at multiple locations CBCS has established a routine in which single use daughter plates holding $2 \mu \mathrm{l}$ of each individual compound solution per well are prepared in multiple copies and then kept at $-18{ }^{\circ} \mathrm{C}$ in a standard freezer until used (plating service provided by iNovacia AB, Stockholm, Sweden). The compound solutions were placed in columns 1 through to 11 in round-bottom Nunc plates (267245).

\section{Screening assay}

The enzymatic assay applied for screening purposes is based on the enzymatic hydrolysis of dCTP by purified human recombinant dCTPase to form dCMP and pyrophosphate. An excess of E.coli inorganic pyrophosphatase (PPase) is added to the reaction mixture to hydrolyse pyrophosphate to inorganic phosphate. Inorganic phosphate is measured by monitoring the absorbance at $630 \mathrm{~nm}$ after incubation with malachite green reagent, as previously described. ${ }^{1}$ dCTPase, PPase and dCTP were diluted in an assay buffer $100 \mathrm{mM}$ Tris-acetate at $\mathrm{pH}$ 8.0, $10 \mathrm{mM}$ magnesium acetate, $100 \mathrm{mM}$ potassium chloride, $0.005 \%$ Tween-20 and $1 \mathrm{mM}$ dithiothreitol (DTT). The contents of the assay ready plates were diluted 100-fold by assay buffer using a PerkinElmer FlexDrop, followed by transfer of 10 $\mu \mathrm{l}$ of the diluted compound solutions to assay plates using a Cybiwell liquid handling station equipped with a 96-well head. Working solutions of dCTPase and inorganic pyrophosphatase (35 $\mu$ l) and dCTP $(65 \mu l)$ were then added to all plates using the FlexDrop. The final conditions in the assay during enzymatic incubation were $25 \mathrm{nM}$ recombinant human dCTPase, $35 \mu \mathrm{M}$ dCTP and $0.2 \mathrm{U} / \mathrm{ml}$ of inorganic pyrophosphatase in a total assay volume of $100 \mu \mathrm{l}$ in a transparent 96-well plate (Nunc 269620). Following incubation of enzymes and substrate at room temperature for $1 \mathrm{~h}$, the reaction was terminated and the signal developed by the addition of $25 \mu \mathrm{l}$ of the malachite green reagent using a MultiDrop (Thermo Scientific). The plates were analysed in a microplate reader using a filter at $630 \mathrm{~nm}$ (Victor 2, PerkinElmer). Reported $I_{50}$ values are the average of two experimental determinations, unless stated otherwise.

\section{Jump Dilution assay}

Performed according to a modified procedure from Copeland et al. ${ }^{2} 500 \mathrm{nM}$ inhibitor $\left(10 \times \mathrm{IC}_{50}\right.$ concentration) was pre incubated for 1 hour with $3.5 \mu \mathrm{M}$ dCTPase with His tag (100 x enzyme concentration) followed by a 100-fold dilution with dCTP substrate solution to a final concentration of 5 $\mathrm{nM}$ compound, $35 \mathrm{nM}$ enzyme and $35 \mu \mathrm{M}$ dCTP substrate. The assay buffer consisted of $100 \mathrm{mM}$ TrisAcetate $(\mathrm{pH} 8), 100 \mathrm{mM}$ potassium chloride, $10 \mathrm{mM}$ magnesium acetate, $1 \mathrm{mM}$ dithiothreitol and $0.005 \%$ Tween 20 . The enzymatic reaction was incubated at different time points and terminated by the addition of Malachite Green reagent followed by an absorbance measurement at $630 \mathrm{~nm}$ on a 
SpectraMax Plate reader after an additional 10 and 15 min incubation. The positive control contained both PPase and dCTPase ( $0 \%$ inhibition) and the negative control contained only PPase $(100 \%$ inhibition).

\section{Differential Scanning Fluorimetry assay}

Differential Scanning Fluorimetry (DSF) was used to identify compounds stabilizing the purified recombinant human dCTPase enzyme. The degree of protein unfolding as a function of temperature is detected by an increase in fluorescence of the Sypro Orange dye upon binding to the hydrophobic parts of the unfolding protein. Compounds that bind to and stabilize the enzyme raise the protein melting point $\left(T_{m}\right)$ leading to temperature shift of the increase in fluorescence upon protein unfolding. The assay buffer in which dCTPase, inhibitors and dye were diluted consisted of $100 \mathrm{mM}$ Tris-acetate $\mathrm{pH} 8.0,100 \mathrm{mM} \mathrm{KCl}, 0.005 \%$ Tween 20 and $1 \mathrm{mM}$ DTT. The assay concentrations used were $0.001-$ $100 \mu \mathrm{M}$ inhibitor, $20 \mu \mathrm{M}$ recombinant human dCTPase and Sypro Orange 5X; 1\% final concentration of DMSO. The assay volumes were $20 \mu \mathrm{l}$ in 96-well Q-PCR plates. A BioRad Q-PCR instrument was used to ramp the temperature from $20-100{ }^{\circ} \mathrm{C}$ at $1{ }^{\circ} \mathrm{C} / \mathrm{min}$ and analysing fluorescence intensity at each step. The Bio-Rad software was used to calculate the $T_{m}$ (negative) of each well of the plate.

\section{NTPases / NUDIX hydrolases selectivity assays}

Performed according to Gad et al. ${ }^{3}$

\section{Selectivity assay for DNA repair enzymes}

DNA repair enzyme activity was measured using an adapted molecular beacon protocol from Svilar et al. ${ }^{4}$ The assay contains a duplex containing a FAM fluorophore on the 5 ' end of one strand oligonucleotide (5'-(FAM)CTGCCAXCACTGCGTCGACCTG-3') and a dabcyl quencher at the 3' end of the complementary strand (5'-CAGGTCGACGCAGTGYYTGGCAG(Dab)-3'. X= modified base, Y: base paired with damaged base when annealed to the FAM-containing strand). Sequential DNA glycosylase and/or AP endonuclease activities leads to the generation of a strand break and dissociation of the FAM-containing strand which generates the signal. Purified DNA glycosylases and AP endonuclease 1 were incubated in reaction buffer containing $25 \mathrm{mM}$ Tris- $\mathrm{HCl} \mathrm{pH} 8.0,15 \mathrm{mM} \mathrm{NaCl}$, $2 \mathrm{mM} \mathrm{MgCl}, 0.0025 \%$ Tween20 and $0.5 \mathrm{mM}$ DTT in black 384-well plates under the following conditions: APE endonuclease 1 (APE1) assay: $X=A P-$ site, $Y=A, 20 \mathrm{nM}$ DNA, $0.2 \mathrm{nM}$ APE1, E.coli

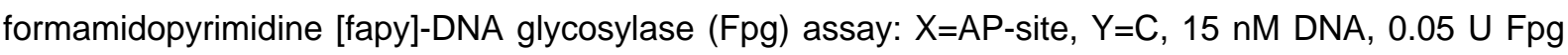
per reaction. Endonuclease 8-like 1 (NEIL1) assay: $X=$ thymine glycol, $Y=A, 10$ nM DNA, 5 nM NEIL1, $2 \mathrm{nM}$ APE1. Methylpurine-DNA glycosylase (MPG) assay: $X=$ inosine, $Y=T, 0.3 \cup$ MPG per reaction, 2 nM APE1. 8-oxoguanine-DNA glycosylase (OGG1) assay: $X=80 x 0, Y=C, 10$ nM DNA, 0.8 nM OGG1, 2 nM APE1. Single-strand selective monofunctional uracil-DNA glycosylase 1 (SMUG1) assay: $\mathrm{X}=$ uracil, $\mathrm{Y}=$ guanine, $250 \mathrm{nM}$ DNA (of which 90\% was unlabelled), $0.25 \cup \mathrm{SMUG1}$ per reaction and 2 nM APE1. Uracil-DNA glycosylase 2 (UNG2) assay: $X=$ uracil, $Y=A, 500$ nM DNA (of which $95 \%$ was 
unlabelled), $0.075 \mathrm{nM}$ UNG2 and $2 \mathrm{nM}$ APE1. None of the reactions yielded any signal on undamaged control duplex oligos $(X=G, Y=C)$ under these conditions (not shown. The reaction buffer was $25 \mathrm{mM}$ tris- $\mathrm{HCl} \mathrm{pH} \mathrm{8.0,15} \mathrm{mM} \mathrm{NaCl}, 2 \mathrm{mM} \mathrm{MgCl}_{2}, 0.0025 \%$ tween20 and $0.5 \mathrm{mM}$ DTT and was performed in black 384-well plates. The signal was read in a Hidex sense plate reader using the 485(10) filter for excitation and the 535(20) filter for emission. Fpg, MPG and SMUG1 were purchased from New England Biolabs while the rest of the enzymes were expressed in bacteria with histidine-tag and purified essentially as described for dCTPase.

\section{Kinase selectivity assays}

For KIT, RET, JAK2, PDGFR-B, PDGFR-A, FMS, FLT-3, IKK2, IKK1, TBK1, IKKe, LMTK3, PDK-1:

Kinase assays. Kinase activity was measured using a LANCE Ultra time-resolved fluorescence resonance energy transfer (TR-FRET) assay and purified recombinant kinases (all from Carna Biosciences, except PDK-1 which was from SignalChem). Kinase assays were carried out in $5 \mu \mathrm{l}$ kinase buffer (50 mM Hepes pH 7.4, $10 \mathrm{mM} \mathrm{MgCl}$, 1 mM EGTA, 2 mM DTT, and 0.01\% Tween-20) with an ATP concentration about two-fold the $K m$ for each enzyme. The conditions for each kinase were as follows (reaction time for each kinase indicated in parenthesis): $4 \mathrm{nM}$ IKKa (90 min) and $1 \mathrm{nM}$ IKK $\beta$ (60 min) with $2 \mu \mathrm{M}$ ATP and Ulight-IKB $\alpha$ (Perkin Elmer); $4 \mathrm{nM}$ IKKE/TBK1 (90 min) with $10 \mu \mathrm{M}$ ATP and Ulight-rpS6 peptide(Perkin Elmer); $0.3 \mathrm{nM}$ JAK2 (60 min) with Ulight-JAK1 (Perkin Elmer) and $10 \mu \mathrm{M}$ ATP; $0.25 \mathrm{nM}$ ABL (90 min) with $2 \mu \mathrm{M}$ ATP and Ulight-pGT (Perkin Elmer); $0.1 \mathrm{nM}$ FLT3 (90 min) with $25 \mu \mathrm{M}$ ATP and Ulight-pGT; $0.3 \mathrm{nM} \mathrm{KIT} \mathrm{(30} \mathrm{min),} 0.4 \mathrm{nM}$ FMS (60 min), $1 \mathrm{nM}$ PDGFR $\alpha$ and $0.5 \mathrm{nM}$ PDGFR $\beta$ all with $10 \mu \mathrm{M}$ ATP and Ulight-pGT; $0.1 \mathrm{nM}$ RET (30 min) with Ulight-pGT and $0.25 \mu \mathrm{M}$ ATP. PDK1 was incubated with $125 \mathrm{nM}$ biotin-PDKTide (AnaSpec) and $0.5 \mu \mathrm{M}$ ATP for 30 $\min$. All kinases were incubated at room temperature for the indicated periods of time in the presence of solvent (1\% DMSO) or $10 \mu \mathrm{M}$ TH620/TH859. Kinase reactions with IKKs were stopped by adding 5 $\mu \mathrm{l}$ of $20 \mathrm{mM}$ EDTA in LANCE detection buffer containing $2 \mathrm{nM}$ of the corresponding Europium-labelled antibody (Eu-plkBa or Eu-prpS6, Perkin Elmer). PDK1 reaction was stopped with $20 \mathrm{mM}$ EDTA/LANCE containing 2 nM Eu-labelled phospho-Thr antibody (Perkin Elmer) and 25 nM Sa-XL665 (CisBio). All Tyrosine kinases were stopped with Eu-PT66 antibody (CisBio) in HTRF detection buffer (CisBio). Following a $2 \mathrm{~h}$ incubation at RT, the TR-FRET signals at 620 and $665 \mathrm{~nm}$ were measured in a CLARIOstar (BMGLabtech) multilabel reader and the 665/620 ratios were used to calculate the percentage of kinase activity remaining in the presence of compound with respect to solvent controls.

\section{For Pim1:}

Active recombinant GST-tagged $\mathrm{M}_{1}-\mathrm{K}_{313}$ Pim1 was purchased from ProQinase (Germany). Assay conditions: Pim1 reaction were performed in $60 \mathrm{mM}$ HEPES/NaOH pH 7.5, 0,0013\% NP40, 10\% DMSO, $3 \mathrm{mM} \mathrm{MnCl} / \mathrm{MgCl}_{2}, 50 \mu \mathrm{M}$ ATP/[r-33P]ATP, $50 \mu \mathrm{M}$ peptide substrate (R11SGRARTSSFAEPGGK), $20 \mathrm{ng}$ active enzyme. The reaction was performed in $10 \mathrm{ml}$ at $30{ }^{\circ} \mathrm{C}$ for 10 min. Reaction was stopped by adding $5 \mu \mathrm{l}$ of phosphoric acid $0.8 \%$. Aliquots $(10 \mu \mathrm{L})$ were then transferred into a P30 Filtermat (PerkinElmer), washed five times with $75 \mathrm{~mm}$ phosphoric acid and 
once with acetone for $5 \mathrm{~min}$. The filter was dried and transferred to a sealable plastic bag, and scintillation cocktail $(4 \mathrm{~mL})$ was added. Spotted reaction was read in a scintillation counter (Trilux, Perkinelmer). To avoid adsorption of enzyme and peptide substrate, low binding plasticware (Eppendorf, LoBind) was used.

For CDK2, CDK5, CDK9, CLK1, CLK2, CLK3, CLK4, CK1, DYKR1A, DYRK1B, DYRK2, DYRK3, GSK3, Ld DYRK4, Pf CLK1, Tb CLK1, Tc CLK1, Lm CLK, Ld DYRK1B, Lm DYRK2, Ld DYRK3, Lm CK1, Cp Lammer, Tg CLK, GI CLK:

Performed according to Tahtouh et al. ${ }^{5}$

\section{DNA intercalation assay}

DNA intercalation was measured in a thiazole orange (ThO) displacement assay performed according to Tse et al. ${ }^{6}$ ThO is a weak intercalating compound that displays a several houndred-fold increase in fluorescence when it binds DNA. Briefly, $50 \mathrm{nM}$ of a duplex oligo substrate DNA repair assays described above is incubated in black 384-well plates with $500 \mathrm{nM}$ ThO in the presence of compound 14 and 18 with DMSO as control under the same buffer conditions as for the DNA repair assays. Propidium iodide, a well-known and frequently used intercalator, was used as positive control. Fluorescence was read after incubation for 5 minutes at room temperature in a Hidex sense plate reader, using the 485(10) filter for excitation and the 535(20) filter for emission.

\section{Photo-stability measurements}

A $10 \mathrm{mM}$ solution DMSO stored in a $2 \mathrm{~mL}$ Eppendorf tube at room temperature under normal laboratory light conditions was periodically monitored by LC-MS over a period of 5 months. $5 \mu \mathrm{L}$ samples were diluted in $200 \mu \mathrm{L}$ of $\mathrm{MeOH}$ and analyzed using LC-MS Method B1090A (see Chemistry General Information) at 305, 254 and $220 \mathrm{nM}$ wavelengths. No UV-active peaks or mass signals appeared during the monitored period.

\section{Genotoxicity assay - Immunofluorescence}

For 53BP1 and $\mathrm{y}-\mathrm{H} 2 \mathrm{AX}$ quantification, $\mathrm{HL} 60$ cells were seeded in a T25 cell culture flasks $\left(8 \times 10^{5}\right.$ cells per flask) and treated with $2.5 \mu \mathrm{M} 18$ for $24 \mathrm{~h}$. Immunofluorescence staining was performed as described by Orta et al. ${ }^{7}$ Images were acquired in a Zeiss LSM-780 confocal microscope with the $63 x$ oil objective. A total of 150 cells /slide were counted and cells with 5 or more co-localized foci of 53BP1 and $\mathrm{Y}-\mathrm{H} 2 \mathrm{AX}$ were considered as positive cells. 


\section{Cell Culture}

HL60 cells were grown in RPMI-Glutamax (Lifetechnologies, cat. Nr. 61870-010), containing $10 \%$ fetal bovine serum (FBS), penicillin $(50 \mathrm{U} / \mathrm{ml})$ and streptomycin $(50 \mu \mathrm{g} / \mathrm{ml})$. Cells were maintained at $37^{\circ} \mathrm{C}$ in a $5 \% \mathrm{CO}_{2}$ atmosphere.

\section{Flow Cytometry}

All experiments were performed on a Navios flow cytometer from Beckman Coulter. For generation of DNA histograms and scoring of (SubG1) dead cells, cells were harvested at the indicated time point, spun down, washed once in cold PBS and then resuspended in propidium iodide buffer $(20 \mathrm{mM}$ Tris $\mathrm{pH} 8.0,50 \mu \mathrm{g} / \mathrm{ml} \mathrm{PI}, 100 \mathrm{mM} \mathrm{NaCl}, 0.1 \% \mathrm{NP} 40,20 \mu \mathrm{g} / \mathrm{ml}$ RNAse). After $1 \mathrm{~h}$ incubation in the dark (4 ${ }^{\circ} \mathrm{C}$ ) the samples were analysed in the FL3 channel on a linear scale for DNA histograms and in the FL2 channel on a logarithmic scale for subG1 content (one log scale below the G1 population was scored as dead cells).

\section{Cellular Thermal Shift (CETSA)}

Performed according to Molina et al., ${ }^{8}$ with the exception of use of Complete protease inhibitor cocktail (Roche) in the lysis buffer.

\section{Viability Assays and Combination Index Analysis}

Resazurin viability assay was performed according to Gad et al. ${ }^{3}$

Combination Index analysis was performed using Compusyn according to Chou. ${ }^{9}$

\section{ADME}

Performed according to Gad et al., ${ }^{3}$ except for the Cytochrome P450 (CYP) inhibition assay. A test compound $(0-100 \mu \mathrm{M})$ and specific probe substrates were pre-incubated with human liver microsomes for 10 minutes, before the reactions were initiated by the addition of NADPH to give a final incubation volume of $100 \mu \mathrm{L}$. After different incubation times (enzyme specific), the reactions were terminated by the addition of ice-cold acetonitrile $(100 \mu \mathrm{L})$ containing internal standard (warfarin, final concentration of $50 \mathrm{nM}$ ). All incubations were performed in duplicate.

For GSH adduct detection, compounds $\mathbf{1 8}$ and $\mathbf{3 0}$ at the final concentration of $10 \mathrm{umol} / \mathrm{L}$ were incubated in the presence of human liver microsomes (HLM, final concentration $1 \mathrm{ug} / \mathrm{ul}$ ) over 30 and $60 \mathrm{~min}$. The incubations were performed in $100 \mathrm{mM} \mathrm{KPO} 4$ buffer, $\mathrm{pH} 7.4$ and in the presence of $5 \mathrm{mM}$ glutathione (GSH). The incubations were started by adding of NADPH at the final concentration of 1 $\mathrm{mM}$. After termination with ice-cold acetonitrile the samples were centrifuged $20 \mathrm{~min}$ at $3500 \mathrm{rpm}$, at $40 \mathrm{C}$ and supernatant was transferred to a new vial. The samples were evaporated and rest was dissolved in acetonitrile/water (50:50, v/v). 
The samples were analyzed using UPLC-Q-Trap mass spectrometer (from AB Sciex) operating in neutral lost and ion precursor modes. No indication of glutathione adducts for the tested compounds were detected.

Following probe substrates were used for measurement of activity of respective cytochrome P450 enzymes: CYP1A2-Phenacetin, CYP2C9-Diclofenac, CYP2C19-S-Mephenytoin, CYP2D6-Bufuralol and CYP3A4-Midazolam and Testostrone.

Different control incubations were included in the assays. As negative controls (single incubations), incubations were performed without NADPH (volume adjusted with phosphate buffer), and without microsomes (only phosphate buffer). In order to verify that the system responds proper to inhibition, the compounds with known inhibitory potency towards each CYP isoform were used as positive controls. The terminated incubations were kept on ice for about 30 minutes before they were centrifuged at ca $3000 \mathrm{rpm}$ for $15 \mathrm{~min}$. The samples were analysed by LC/MS/MS. Standard curves were prepared for the substrate metabolites in $50 \mathrm{mM}$ phosphate buffer, $\mathrm{pH} 7.4$, in appropriate ranges (100 $\mu \mathrm{L}$ total volume).

\section{Data analysis and statistics}

All statistical significant difference was calculated in Excel or GraphPad by using the student t-test 
Copies of NMR spectra for relevant compounds (14,18 and 30$)$
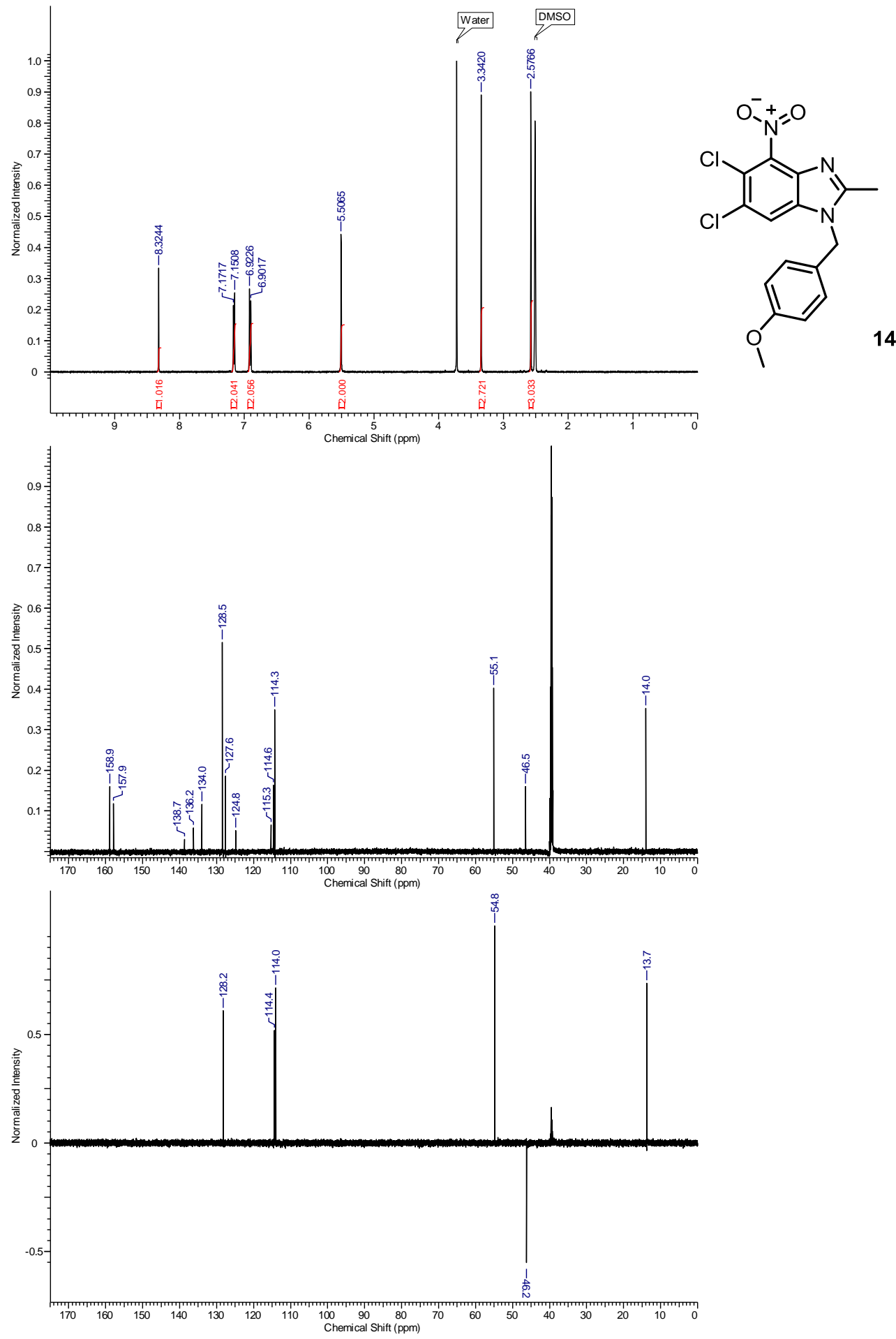

${ }^{1} \mathrm{H}$ and ${ }^{13} \mathrm{C}$ NMR spectra for compound 14 

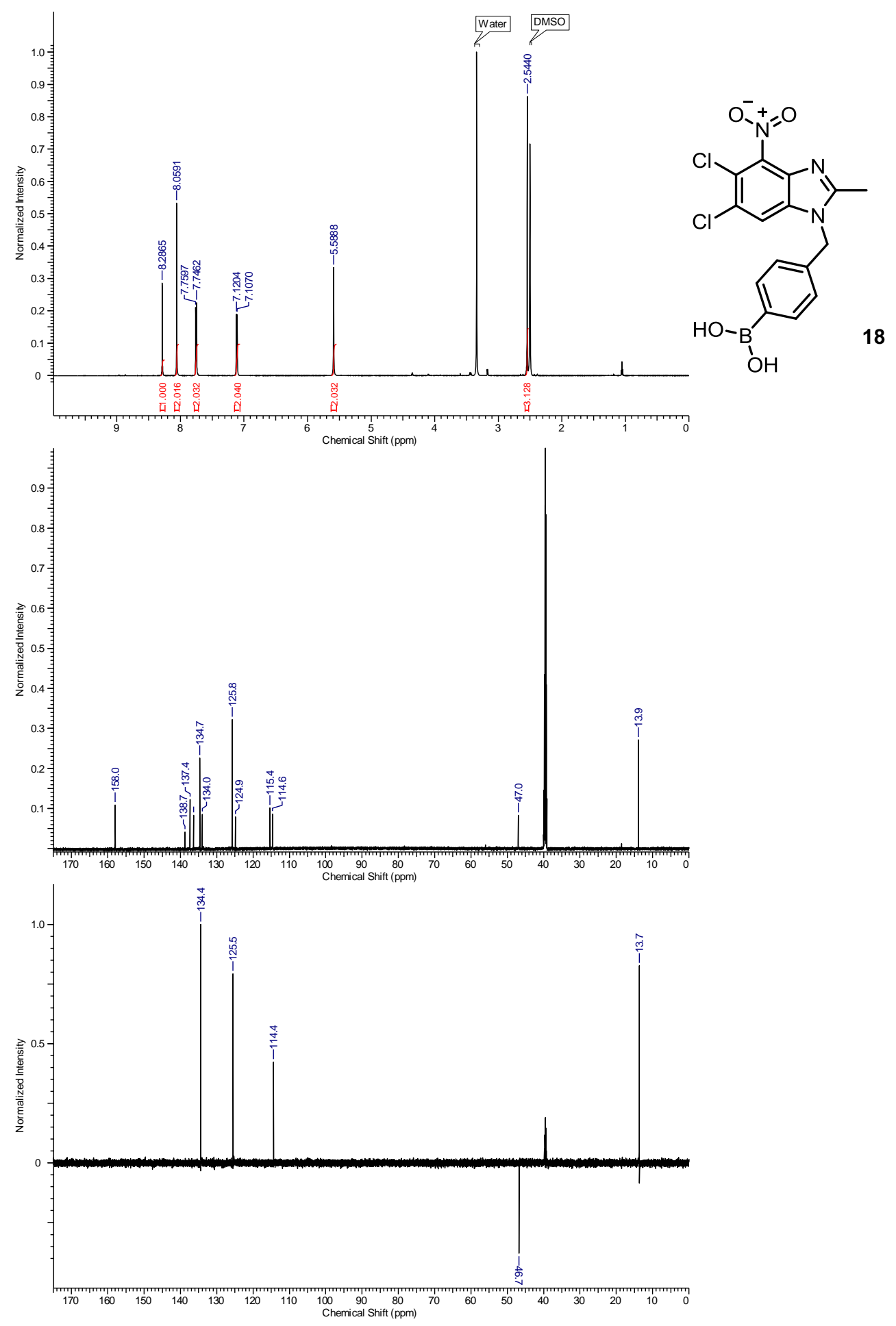

${ }^{1} \mathrm{H}$ and ${ }^{13} \mathrm{C}$ NMR spectra for compound 18 

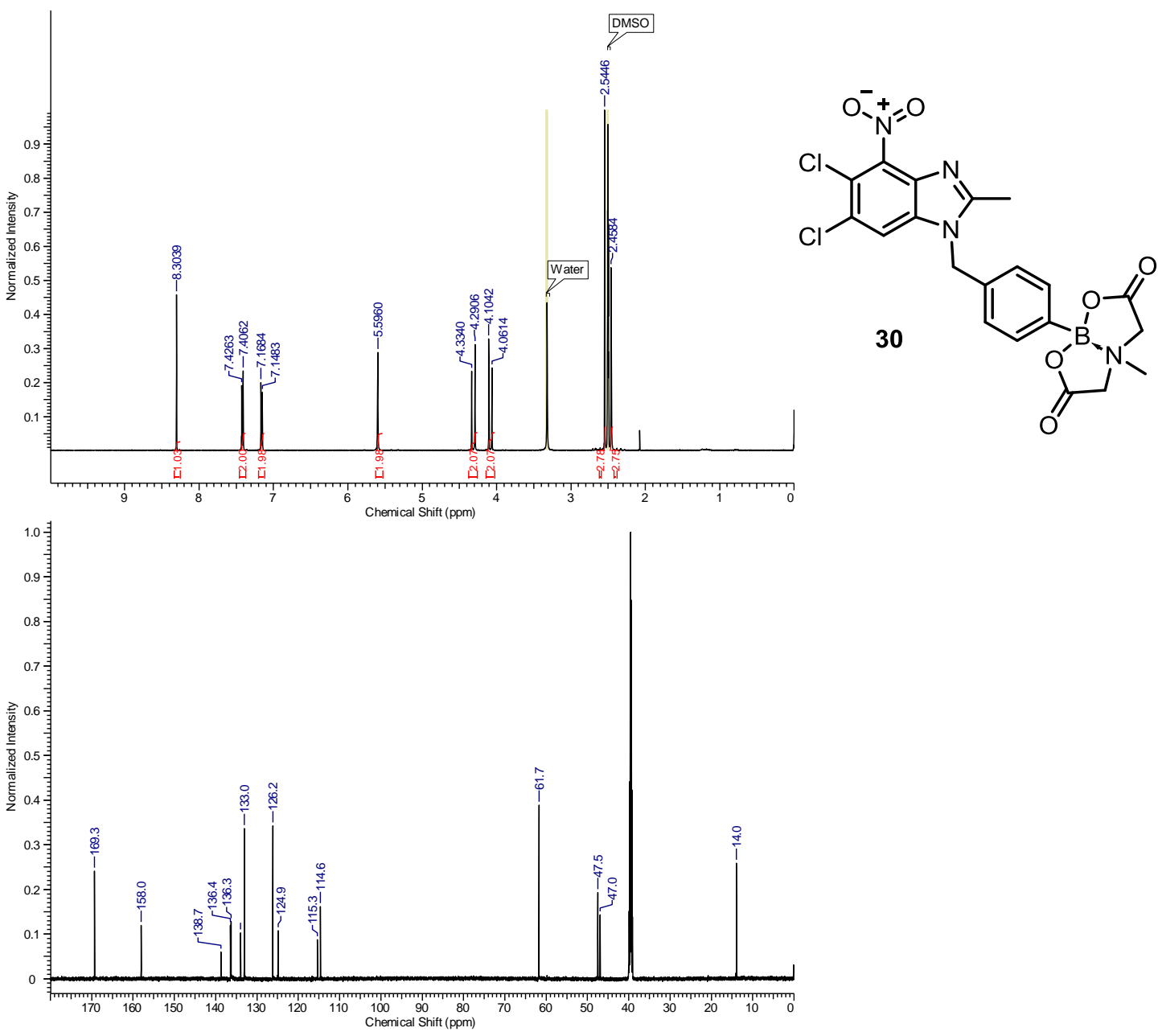

${ }^{1} \mathrm{H}$ and ${ }^{13} \mathrm{C}$ NMR spectra for compound $\mathbf{3 0}$ 


\section{Additional References}

orthophosphate determination and its use in alkaline phosphas Biochem. 1988, 171, 266-70.

2. Copeland, R. A.; Basavapathruni, A.; Moyer, M.; Scott, M. P. Impact of enzyme concentration and residence time on apparent activity recovery in jump dilution analysis. Anal Biochem 2011, 416, 206-10.

3. $\quad$ Gad, H.; Koolmeister, T.; Jemth, A.-S.; Eshtad, S.; Jacques, S. A.; Strom, C. E.; Svensson, L. M.; Schultz, N.; Lundback, T.; Einarsdottir, B. O.; Saleh, A.; Gokturk, C.; Baranczewski, P.; Svensson, R.; Berntsson, R. P. A.; Gustafsson, R.; Stromberg, K.; Sanjiv, K.; Jacques-Cordonnier, M.-C.; Desroses, M.; Gustavsson, A.-L.; Olofsson, R.; Johansson, F.; Homan, E. J.; Loseva, O.; Brautigam, L.; Johansson, L.; Hoglund, A.; Hagenkort, A.; Pham, T.; Altun, M.; Gaugaz, F. Z.; Vikingsson, S.; Evers, B.; Henriksson, M.; Vallin, K. S. A.; Wallner, O. A.; Hammarstrom, L. G. J.; Wiita, E.; Almlof, I.; Kalderen, C.; Axelsson, H.; Djureinovic, T.; Puigvert, J. C.; Haggblad, M.; Jeppsson, F.; Martens, U.; Lundin, C.; Lundgren, B.; Granelli, I.; Jensen, A. J.; Artursson, P.; Nilsson, J. A.; Stenmark, P.; Scobie, M.; Berglund, U. W.; Helleday, T. MTH1 inhibition eradicates cancer by preventing sanitation of the dNTP pool. Nature 2014, 508, 215-221.

4. $\quad$ Svilar, D.; Vens, C.; Sobol, R. W. Quantitative, real-time analysis of base excision repair activity in cell lysates utilizing lesion-specific molecular beacons. $J$ Vis Exp 2012, e4168.

5. $\quad$ Tahtouh, T.; Elkins, J. M.; Filippakopoulos, P.; Soundararajan, M.; Burgy, G.; Durieu, E.; Cochet, C.; Schmid, R. S.; Lo, D. C.; Delhommel, F.; Oberholzer, A. E.; Pearl, L. H.; Carreaux, F.; Bazureau, J.-P.; Knapp, S.; Meijer, L. Selectivity, Cocrystal Structures, and Neuroprotective Properties of Leucettines, a Family of Protein Kinase Inhibitors Derived from the Marine Sponge Alkaloid Leucettamine B. J. Med. Chem. 2012, 55, 9312-9330.

$6 . \quad$ Tse, W. C.; Boger, D. L. A fluorescent intercalator displacement assay for establishing DNA binding selectivity and affinity. Acc Chem Res 2004, 37, 61-9.

7. $\quad$ Orta, M. L.; Hoglund, A.; Calderon-Montano, J. M.; Dominguez, I.; Burgos-Moron, E.; Visnes, T.; Pastor, N.; Strom, C.; Lopez-lazaro, M.; Helleday, T. The PARP inhibitor Olaparib disrupts base excision repair of 5-aza-2'-deoxycytidine lesions. Nucleic Acids Res 2014, 42, 9108-20.

$8 . \quad$ Molina, D. M.; Jafari, R.; Ignatushchenko, M.; Seki, T.; Larsson, E. A.; Dan, C.; Sreekumar, L.; Cao, Y.; Nordlund, P. Monitoring Drug Target Engagement in Cells and Tissues Using the Cellular Thermal Shift Assay. Science 2013, 341, 84-87.

9. Chou, T.-C. Drug Combination Studies and Their Synergy Quantification Using the Chou-Talalay Method. Cancer Res. 2010, 70, 440-446. 